\title{
Developing a Research Agenda through Pitching
}

\author{
Victor Maxwell a,1 \\ ${ }^{a}$ University of Queensland Business School, Australia
}

\begin{abstract}
This paper details my use of the pitching template framework (Faff, 2015) in the development of the research agenda for my $\mathrm{PhD}$ at the University of Queensland (UQ) Business School. I used the pitching template once for the research proposal submitted when applying for the $\mathrm{PhD}$ program and twice more during the early months of the program. Use of the pitching template framework appears to have helped progress my thinking about and communication of my research agenda. This is as anecdotal evidence of the pitching template's benefits for researchers.
\end{abstract}

Keywords: Pitching Research; Clean Tech; Information Systems

JEL codes: A20, Q55, Q57

\section{Introduction}

The point of departure for the following paper is the pitching template framework developed in Faff (2015) and expanded upon in Faff (2017) and Faff and Kastelle (2016). I first encountered the pitching template framework as part of the application process for the PhD program at the UQ Business School (I am currently enrolled in this program). I later gained a more thorough understanding of the pitching template framework during my participation in the course Research Process in Business offered to RHD students at UQ Business School. Herein, I discuss the pitching template framework within the context of its practical application in the case of my own research conducted as part of a PhD program at the UQ School of Business. Specifically, the paper examines three pitching templates that I completed at

${ }^{1}$ Corresponding author: University of Queensland Business School; Room 101, Social Sciences Annexe Building, St Lucia Campus, Brisbane, Australia; tel. (+61) 73365 8828; email address: v.maxwell@business.uq.edu.au 
different stages of the research process. This provides the basis for a qualitative assessment of how the complexity and organization of my thoughts has developed through the early stages of my PhD program.

To be sure, the intention of this paper is to illustrate the process of developing a research agenda through use of the pitching template framework. Therefore, I do not mean to present the particular research agenda discussed herein as a completed work but rather an ongoing process. Nevertheless, the research agenda is "real" in the sense of Faff (2017) and represents a "yet to be executed study."

The paper is organized as follows. Section 2 gives an overview of the pitching template framework. This section is divided into two parts, the first dealing with the "scholarly" pitching research template and the second with the pitching research for engagement and impact template. Section 3 details how I applied the framework to my own research. This section is comprised of three parts. I first describe my initial use of the pitching template framework during the time when I was applying for the UQ Business School PhD program; secondly, the use of the "scholarly" template during my time in the Research Process in Business course; and finally, my use of the engagement and impact template towards the end of that same course. Thus, Section 3 provides an overview of how the organization of my thoughts on and communication about my PhD research topic has evolved during this early part of the $\mathrm{PhD}$ program and what the pitching template's role has been in that. Section 4 provides some concluding remarks.

\section{Overview of Pitching Template Framework}

\subsection{Pitching Research}

The pitching template framework developed in Faff $(2015$, 2017) provides a methodical approach for researchers who are endeavoring to organize their thoughts around a new research idea and communicate this idea to others. Faff stresses that the two biggest obstacles faced by a researcher at this early stage are beginning and finishing the research. He rightly states that overcoming the latter obstacle is dependent on the success in overcoming the former but also points out that the initial success is itself dependent on having "a good grasp of where it is you are heading." In other words, there is little benefit in starting a research project within a certain field when that project is based on an idea that will ultimately make a negligible contribution to that field. Of course, one may never know the outcome of an endeavor whose results are consigned to posterity. Nevertheless, the pitching template framework seeks to help researchers avoid unproductive pursuits by encouraging them to provide essential information accessibly to collaborators and other peers who are able to provide feedback on whether or not the proposed research project is 
feasible. Furthermore, the template allows the researcher to organize their thoughts early on in a clear and concise manner.

Tables 1 and 2 show completed pitching research templates. Note that the completed pitches fulfill the two main purposes of the pitching template framework: to be brief and to cover the essential points. In the first case, the completed pitches are each no more than two pages in length. In the second case, the completed pitches do well in populating all of the template's fields (the first populates all but the last field).

\subsection{Pitching Research for Engagement and Impact}

Building on earlier work, Faff and Kastelle (2016) focus on non-academic use of the pitching template framework. They propose that engagement and impact are two key components of successful dissemination of academic research to the broader public. The authors define engagement as the mutually beneficial interaction between researchers and their larger communities. This includes the reciprocal exchange of knowledge and understanding. Impact refers to the demonstrable socioeconomic contributions from research. Because all too often the broader community does not immediately recognize the contribution of particular research, the pitching research for engagement and impact template seeks to provide researchers with a tool by which they can more readily demonstrate the value of their research to key non-academic stakeholders.

Accordingly, Table 3 displays a completed pitching research for engagement and impact template. Note the difference between the prompting questions in this template and the original "scholarly" template. For example, while item C in the original template prompts the user to list three key papers that inform their research, the same item in the engagement and impact template prompts the user to list three key industry or external triggers that motivate their research. This difference in prompting questions illustrates the deeper difference in approach between the two templates. While the one steers the user towards framing their research in language that is recognizable and appreciated in academic circles, the other encourages the user to engage the broader community from the start, even before they attempt to communicate their idea to the stakeholders of that community.

\section{Application of Pitching Template Framework}

\subsection{Initial Pitch}

My first experience with the pitching template framework came during the time when I first applied for the PhD program at the UQ Business School. I had met with my future supervisors who had encouraged me to use the pitching template in order to develop the research proposal, which was a required component of the application process. My potential $\mathrm{PhD}$ would have funding from a grant from the Australian 
Research Council (ARC) that had been awarded to my supervisors to fund the research project: "Australia's climate strategy and positioning for the clean tech revolution" (University of Queensland, 2016). Knowing that this was the case, I wanted to write a research proposal that would clearly connect to this lager research program and have its own distinct merit. Table 1 shows the completed pitching template for this initial research proposal.

It is instructive to look at the responses given in the Initial Research Pitch, and especially the underlying theme of the research presented therein. The research pitch attempts to define the notion of "clean tech revolution" which is used in the ARC grant proposal. Specifically, Section D (Motivation/Puzzle) defines clean tech as renewable energy technologies. Revolution refers to the transition from fossil fuel based to renewable energy based systems. Beginning with Section B (Basic Research Question), I refer to the transition as a "technological breakthrough" which could potentially affect the "current economic model." Section C (Key Papers) attempts to contextualize the proposed research by listing relevant source material. The first two papers (Gunderson \& Holling, 2002; Linnenluecke \& Smith, 2015), deal with technological change, and specifically how human society and the environment interact to bring about these changes. The third paper (Hong et al., 2008), has to do with how the availability and transmission of information about new technology affects economic decision-making. The proposed research seeks to build off these key papers and accordingly section D speaks about how climate change is driving the transition to renewable energy systems. However, environmental and social factors affect the availability of energy from, and information about, these systems and these factors operate on a shorter time scale than those that affect the availability of fossil fuel energy. While this point is not explicitly stated, it is implied in the statements about intermittency, flexibility, and decentralization found in section D of the template. The motivation leads to the puzzle of how to assess the "clean tech revolution" within the frameworks of technological change and broader socioeconomic paradigm shifts.

The Initial Research Pitch continues with the practical details of the research proposal, the so-called "three, two, one" sections of the pitching template framework. Section E (Idea) states that the research will seek to assess the optimal economic strategy for the transition to decentralized renewable energy systems. This statement presupposes that investors see decentralized renewable energy systems as the way forward but fails to mention exactly who are these investors. Section J (Contribution) answers this question, at least somewhat, by stating that the research seeks to inform policy makers. Section $\mathrm{E}$ does however make clear that the research is concerned with the intersection of energy and economy. Section F (Data) explains that the research intends to compare renewable energy transition with past technological breakthroughs by comparing the policy decisions and economic consequences surrounding these. In Section G (Tools), I state that the proposed research intends to mix qualitative and quantitative methods. 
In section $\mathrm{H}$ (What's New), the proposed research is presented as having some degree of novelty in that it seeks to frame the transition to decentralized renewable energy systems as a technological breakthrough but with the added dimension that the breakthrough is being driven by both anthropogenic (new man-made technology) and non-anthropogenic (environmental boundaries) dimensions. The interdisciplinary approach of the research is also regarded as something "new." However, the argument for novelty is somewhat invalidated in Section I (So What), by stating that the research merely fills gaps. Nevertheless, as stated in Section J (Contribution), the research is important as it might allow policy makers to make better-informed decisions.

\subsection{1 'Mickey Mouse' diagram}

Faff (2017) suggests using a Venn diagram as a way to organize the main ideas presented in a pitch, and visualize their interconnection. This "Mickey Mouse" diagram has the further benefit of helping the researcher asses the novelty of their research. Previous pitch letters have demonstrated the use of the 'Mickey Mouse' diagram. Of particular relevance to the topic of my Initial Research Pitch are Shahzad (2016) and Rekker (2016) who both focus on business strategies for climate change adaptation.

Figure 1 shows the Venn diagram that I constructed for my Initial Research Pitch. I intend to investigate the interconnections between planetary boundaries, technological innovation, and economic modelling, as there appears to be meaningful overlap between these three categories. In developing my research, I have chosen three key papers, each of which fits into the area of overlap of at least two of the three categories. Using the methodology described in the pitch, I hope to be able to make a novel contribution that sits at the intersection of all three categories.

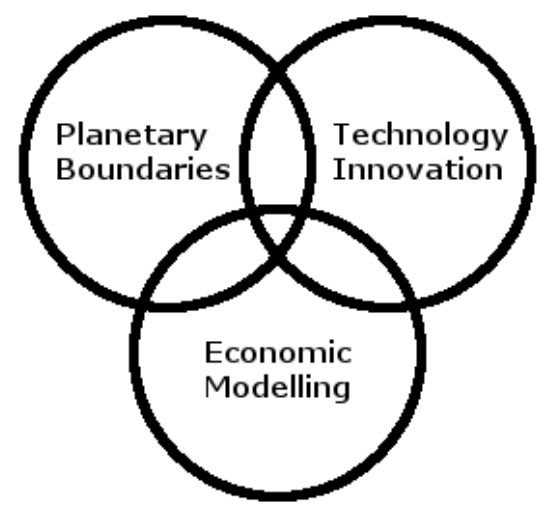

Figure 1. Mickey Mouse diagram characterizing novelty of research idea in Initial Pitch 
The pitching template, and associated tools such as the 'Mickey Mouse' diagram, helped me to organize my thoughts and quickly and efficiently write a coherent research proposal. I believe that it played a part in my being successfully awarded the scholarship position. Following the application process, I did not think much about the pitching template framework until I enrolled in the Research Process in Business course during the 1 st semester of my $\mathrm{PhD}$ program.

\subsection{Second Pitch}

Coming into the Research Process in Business course at UQ Business School, I had a general idea of what the research agenda for my $\mathrm{PhD}$ thesis would be. However, I had not made much progress beyond that described in the Initial Research Pitch. The objectives of the course included the delivery of completed pitching research templates and the presentation thereof. This, along with the more thorough understanding of how to use the template, which I acquired from participating in the course, allowed me to move from a general idea to something more specific. This move took place in two stages: refining the "scholarly" pitch of the proposed research, and adapting the research for engagement and impact. The Second Research Pitch (Table 2) illustrates my thinking at the end of the first stage.

The Second Research Pitch continues with the themes introduced in the Initial Research Pitch. Phrased as questions, these are: what are the biophysical boundary conditions in which socio-economic systems may sustainably function and how can current energy and economic systems be transformed to account for these boundaries. Thus section C (Key Papers) includes sources which deal with explaining what are these boundaries (Georgescu-Roegen, 1971), why they should be respected (Faber, et al., 1996), and how we can assess where particular socioeconomic systems (national level) sit with regard to them (O'Neill, 2015). It is interesting to note that none of the key papers used in the initial pitch are included in the second pitch. While the key papers in each share common themes, the choice of papers in the second pitch firmly places the proposed research within the academic discipline of Ecological Economics.

Not only does the Second Research Pitch focus in on a particular and established research area, it also narrows the focus of the research from the general agenda proposed in the Initial Research Pitch. Thus the Basic Research Question of section B: How do producer-consumers in smart grid networks behave? So the new research proposal seeks to analyze the behavior of an economic agent, the producerconsumer, which has risen out of the transition to decentralized renewable energy systems, smart grids, and compare this behavior to that of economic agents operating under centralized fossil fuel energy systems. As explained in section D (Motivation/Puzzle), this change in behavior might tell us something about how 
energy systems (and larger socio-economic systems) can be adapted to best deal with the boundaries imposed by climate change and resource availability.

The "three" sections (E through G), outline how the research will be conducted, stressing that game theory will be essential in modeling the behavior of the producerconsumers. However, as stated in section G (Tools), although use of game theory makes sense intuitively, I am not very familiar with the details of the theory as of yet. The assumption is that I will learn game theory through the process of conducting the research. While this might be acceptable approach, it begs the question of whether or not I have a "good grasp" of where it is I am heading. Fortunately, or not, as explained in section K (Other Considerations), there has been a prior investigation of smart grid systems using game theory. This does not completely rule out the novelty of the proposed research however. As stated in the "two" sections (H and I) the proposed research seeks to understand how an economic agents' decision making is affected by their awareness of biophysical boundary conditions and not just notions of maximizing economic utility.

In assessing the progress made in my thinking about and communicating of my research agenda, it is important to note my claim in the "one" section $\mathrm{J}$ (Contribution). As opposed to the Initial Research Pitch, where I sought merely to fill a gap in the body of research, the contribution of the proposed research in the Second Research pitch is that it adds usefully to a growing body of knowledge and thus helps to progress the field of Ecological Economics.

\subsection{Third Pitch (Engagement and Impact)}

Towards the end of the Research Process in Business course, students were introduced to the pitching research for engagement and impact template (Faff \& Kastelle, 2016). Researchers in the business field, perhaps more so than those in other academic fields, should be mindful of the potential practical application of new research already at the point of commencement. Of course, they should not become overzealous in their desire to conduct research with real world application as this may detract from the academic nature of their work and lead to bias. Combined use of the "scholarly" and engagement and impact pitching templates may provide a means of balancing researcher's academic and pragmatic objectives.

Table 3 shows the completed Third Pitch (Engagement and Impact). As with the Second Research Pitch, the Third Pitch maintains the overall theme of the Initial Research pitch. Moreover, as was the case with moving from the initial to the second pitch, the organization of thought around and communication of the research topic is better focused. Whereas the Second Research Pitch deals with smart grids, a component of distributed renewable energy systems, the Third Pitch deals with the 
transfer of information, a function of the smart grid. However, the goal of increasing the adoption of distributed renewable energy systems remains the same.

As shown in section C (Key Industry/External Triggers), the last few years have seen an increased recognition of the biophysical boundaries which limit socio-economic activity (general consensus on anthropogenic climate change and push for increased use of renewable energy) (Edenhofer et al., 2012). At the same time, there have been recent rapid technological advances with regard to how information distribution across socio-economic networks (Internet of Things, Blockchain) (Gubbi et al., 2013). Efforts to create a sustainable future for humanity requires that one acknowledge both of these trends (Moss et al., 2010). Thus, as explained in section D (Motivation/Problem), I am proposing to investigate how the transfer of information affects the volatility of renewable energy system and assets tied to these systems. It is interesting to note that the topic of how information transfer effects economic decision-making was first brought up in the third key paper of the Initial Research Pitch.

The "three" sections (E through G) outline the practical details of who will benefit from the research, how they will benefit, and what I need to help realize this benefit. There is a general notion of inclusion running through these sections as the list of stakeholders is broad and I have taken care to address how each of these will derive value from the research. Moreover, section $G$ (Resources) shows how the success of the research depends on contributions from each of these stakeholders. This theme of inclusion is also present in section H (Communication Strategy), which makes clear that I intend to make the results of the research transparent.

Sections I (Metrics) and J (Impact) illustrate the ultimate social and environmental justice goals of the research proposal, namely the reduction of $\mathrm{CO} 2$ in the atmosphere and the more egalitarian distribution of wealth. Again, these themes run through all three research pitches. In the third pitch however, I put the themes to practical use as a way of assessing the success of the research and framing the impact on stakeholders. As explained in section K (Other Considerations) the ideals of my academic pursuits and the practicality of delivering a beneficial product to stakeholders do not seem to be in conflict.

\section{Conclusion}

The preceding paper has examined my use of the pitching template framework in developing my thoughts on and communication around the research agenda that I will pursue during my PhD at the UQ Business School. There is evidence to suggest that use of the pitching template framework was indeed beneficial to this development. There is a clear line of progression evident in the three completed pitch templates examined here. Whether or not I would have obtained the same results without the use of the pitching template framework we may not know. 
Nevertheless, I feel that use of the framework has helped me focus in on a feasible research agenda within a relatively short time.

As mentioned in the Introduction, the research agenda presented herein is in the midst of an ongoing process. Moving forward, I may choose to combine aspects of the three pitches. For example, looking at how the availability and transfer of information affects volatility, as per the third pitch, does not necessarily exclude a behavioral economic analysis of the type I had intended to pursue in the second pitch. Similarly, attempting to engage with industry partners and other stakeholders does not necessarily exclude situating my research within the field of Ecological Economics. Finally, the notions of technological breakthrough explored in the first pitch may still inform the theoretical framework of my research regardless of how I choose to move forward empirically.

Using the pitching templates has not only been an interesting and thought provoking academic exercise, but also delivered some tangible benefits for my development as a researcher. Therefore, I would strongly encourage other researchers to consider using the pitching template framework.

\section{References}

Edenhofer, O., Madruga, R. P. \& Sokona, Y. (2012) Renewable Energy Sources and Climate Change Mitigation, Cambridge: Cambridge University Press

Faber, M., Manstetten, R. \& Proops, J. (1996) Ecological Economics: Concepts and Methods. Cheltenham: Edward Elgar

Faff, R. (2015) “A Simple Template for Pitching Research", Accounting and Finance, Issue 55: 311-336

Faff, R. (2017) "Pitching Research", Available at: https://papers.ssrn.com/sol3/papers.cfm?abstract_id=2462059

Faff, R. \& Kastelle, T. (2016) "Pitching Research for Engagement and Impact", Available at: https://papers.ssrn.com/sol3/papers.cfm?abstract_id=2813096

Georgescu-Roegen, N. (1971) The Entropy Law and the Economic Process. Cambridge, Massachusetts: Harvard university Press

Gubbi, J., Buyya, R., Marusic, S. \& Palaniswami, M. (2013) "Internet of Things (IoT): A vision, architectural elements, and future directions", Future Generation Computer Systems, vol. 29(7): 1645-1660

Gunderson, L. \& Holling, C. (2002) Panarchy: Understanding Transformations in Human and Natural Systems. Washington, D.C.: Island Press

Hong, H., Scheinkman, J. \& Xiong, W. (2008) "Advisors and asset prices: A model of the origins of bubbles", Journal of Financial Economics, vol. 89(2), pp. 268-287

Linnenluecke, M. \& Smith, T. (2015) Climate (In)Action: A Real Options approach to investigate the impact of climate change policy on new technology uptake. Athens, European Group for Organization Studies. 
Moss, R. H., Edmonds, J.A., Hibbard, K.A., Manning, M.R., Rose, S.K., van Vuuren, D.P., Carter, T.R., Emori, S., Kainuma, M., Kram, T., Meehl, G.A., Mitchell, J.F.B., Nakicenovic, N., Riahi, K., Smith, S.J., Stouffer, R.J., Thomson, A.M., Weyant, J.P. \& Wilbanks, T.J. (2010) "The next generation of scenarios for climate change research and assessment", Nature, vol. 463: $747-756$

O'Neill, D. (2015) "The proximity of nations to a socially sustainable steady-state economy", Journal of Clean Production, vol. 108: 1213-1231

Rekker, S. (2016) "Converting planetary boundaries into action, a new approach to meeting global greenhouse gas targets: A pitch", Accounting and Management Information Systems, vol. 15(1): 160-167

Shahzad, S. K. (2016) "Private firms' adaptation to climate change within the context of developing countries: A pitch", Accounting and Management Information Systems, vol. 15(1): 168-177

University of Queensland, 2016. Australia's Climate Strategy and Positioning for the Clean Tech Revolution (2016-2020), Available at:

http://researchers.uq.edu.au/research-project/27178 [Accessed 101 2017] 
Table 1. Initial Research Pitch on Clean Tech

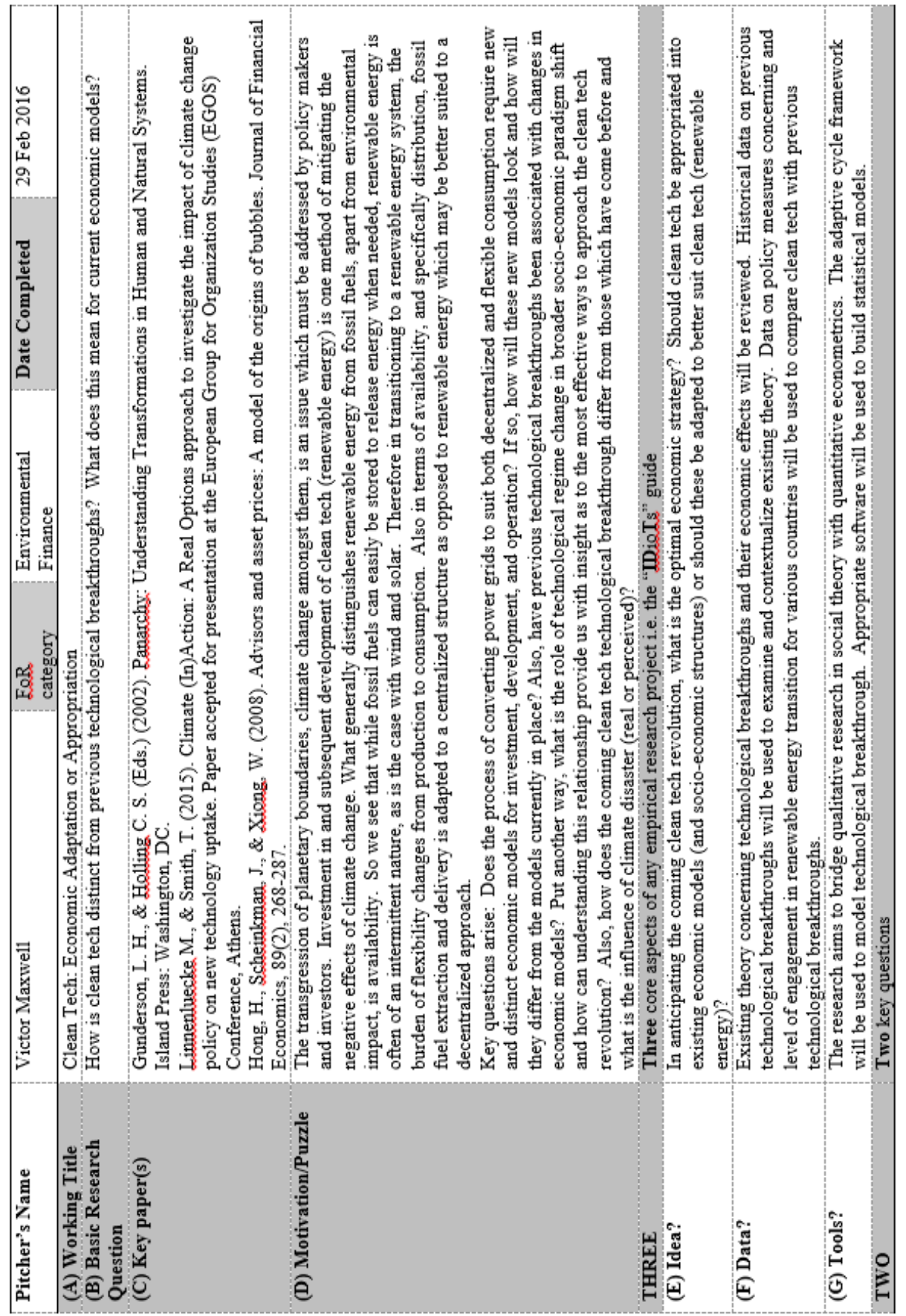




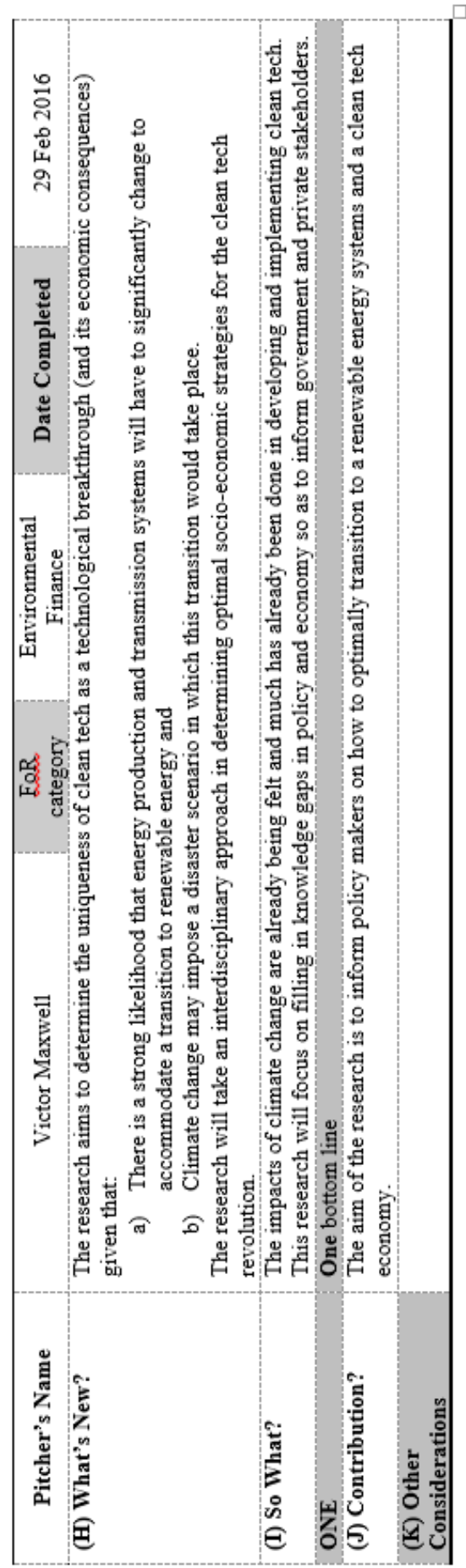

Vol. 16, No. 2 
Table 2. Second Research Pitch on Smart Grid Games

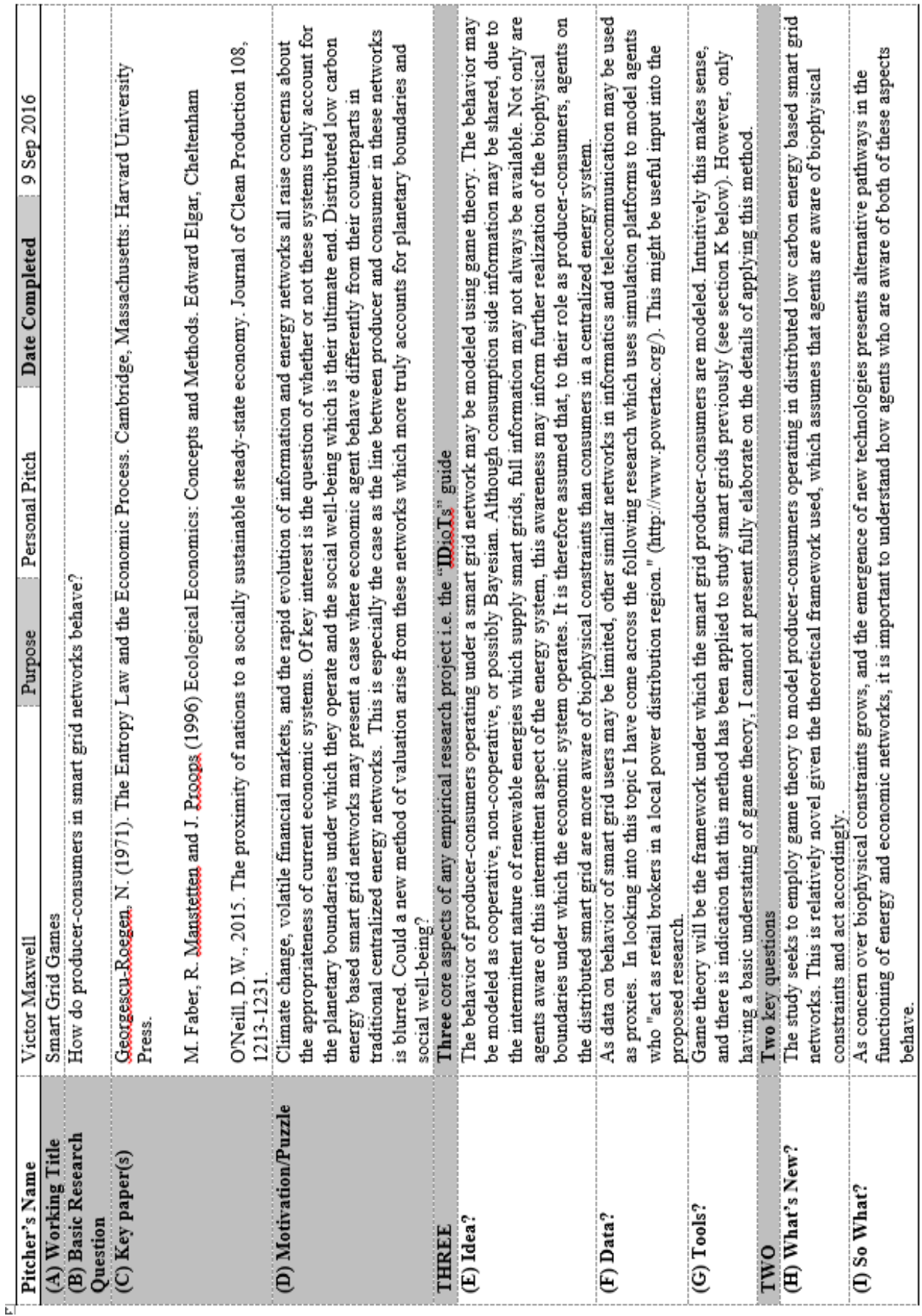




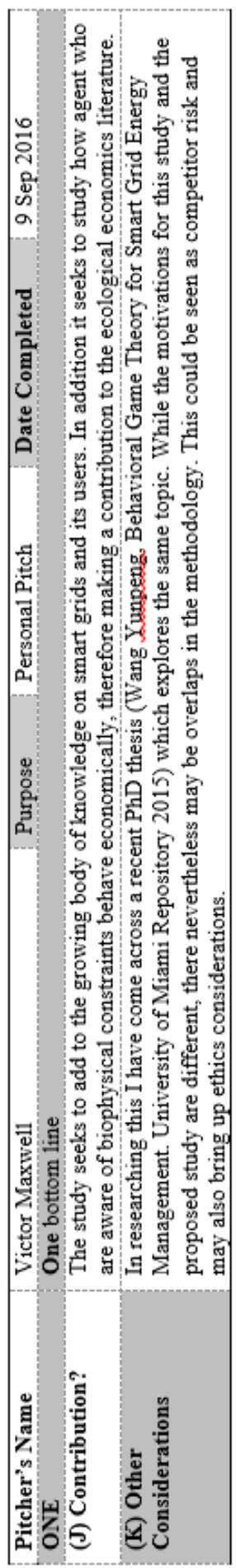

Vol. 16, No. 2 
Table 3. Third Research Pitch (Engagement and Impact) on Blockchain in Energy Systems

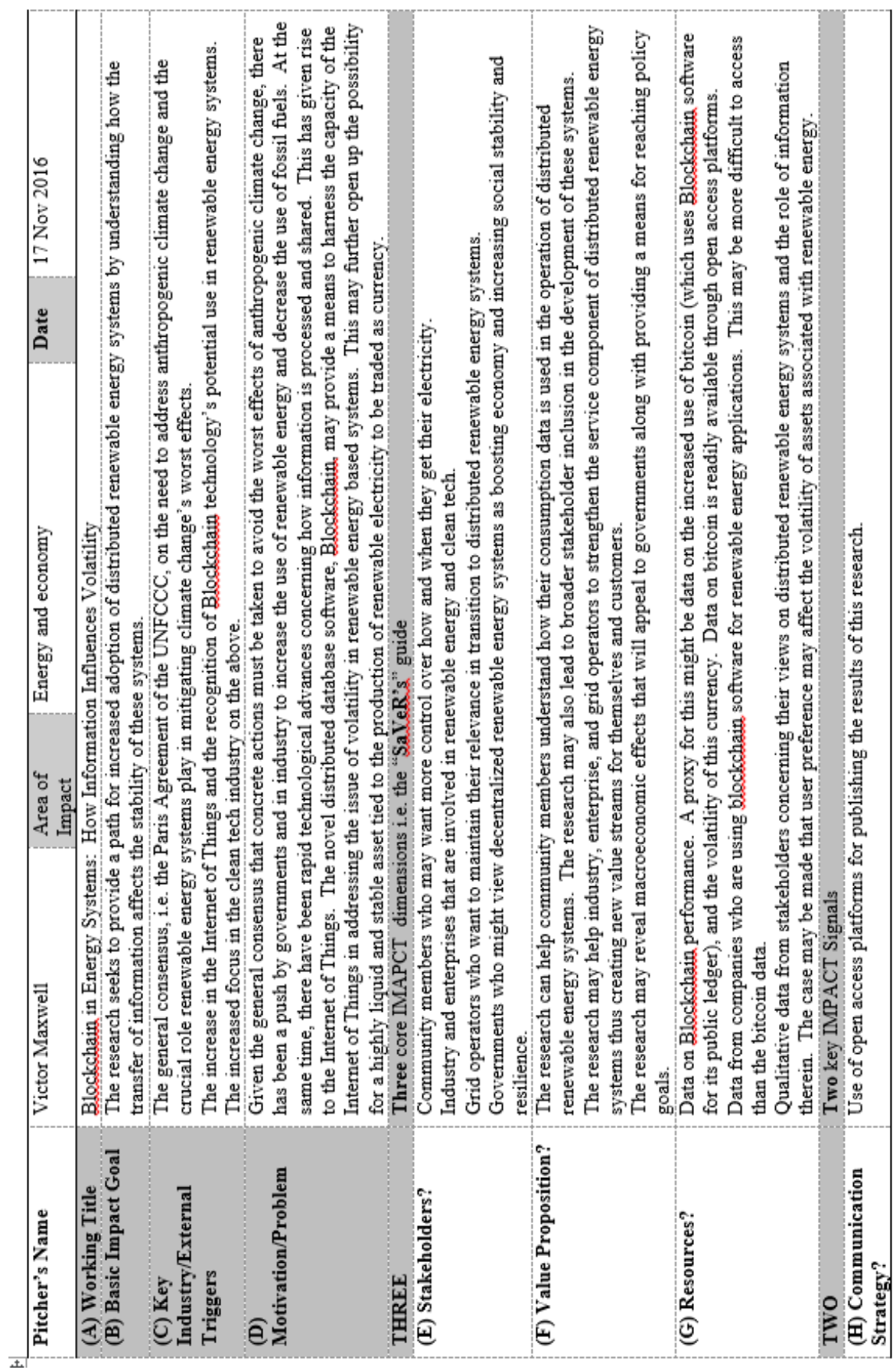




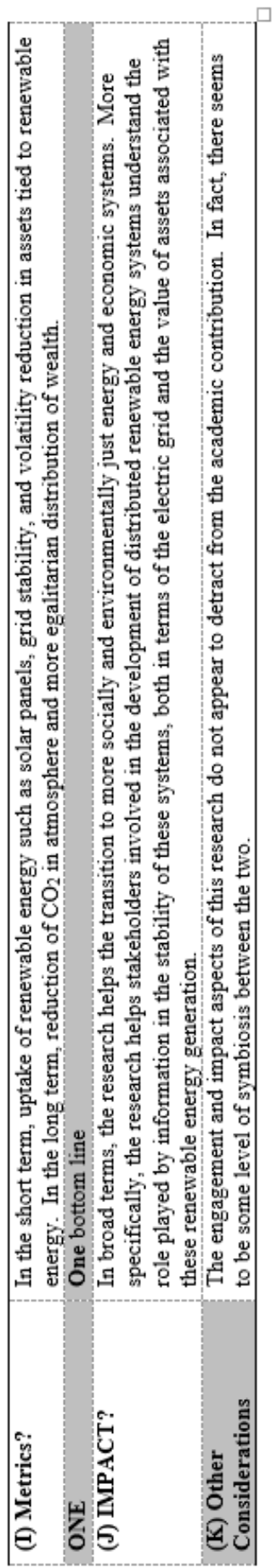

Vol. 16, No. 2 